
gradient

\title{
Understanding what shapes varying perceptions of the procedural fairness of transboundary environmental decision-making processes
}

\author{
Matthew Hamilton $^{1}$
}

\begin{abstract}
The effectiveness of collaborative environmental decision-making processes hinges on the degree to which participating stakeholder groups (i.e., policy actors) perceive those processes to be fair. However, there is limited understanding of the factors that shape actors' perceptions of the fairness of decision-making processes, a concept known as perceived procedural fairness. I develop and test a set of hypotheses about the conditions under which actors that participate in the same environmental decision-making processes perceive the fairness of those processes differently. The study draws upon data from a survey of policy actors participating in task forces, steering committees, and other forums that guide climate change adaptation decision-making in the Lake Victoria basin in East Africa. These actors vary significantly in power and capacity, which raises questions of the degree to which forums provide meaningful opportunities for all actors to contribute to decision making. Findings indicate that among pairs of actors participating in any given forum, satisfaction with procedural fairness is higher among actors with greater social capital, operating at higher administrative levels, and with larger numbers of staff members. Additionally, donor organizations perceived higher levels of procedural fairness compared to civil society, government, and international nongovernmental organizations. These results have implications for efforts to improve the efficacy and legitimacy of environmental policy making in the Lake Victoria basin, as well as other transboundary governance systems in developing regions.
\end{abstract}

Key Words: collaborative governance; East Africa; lake basins; policy networks; social processes

\section{INTRODUCTION}

Collaborative models of environmental governance have proliferated over the past several decades. Such models, which emphasize the participation of diverse sets of policy actors (i.e., stakeholder groups) in consensus-based decision-making processes, have been characterized as alternatives to conflictprone centralized policy processes (Ansell and Gash 2008) and as a means for promoting flexibility and policy learning in response to environmental change (Armitage et al. 2008). While recognizing these prospective benefits, scholarship on collaborative environmental governance has also highlighted potential limitations, including an emphasis on social interaction (e.g., among actors with dissimilar policy preferences) at the expense of action (Lubell 2004). Particularly in environmental governance contexts in which resources, authority, and power are unequally distributed among policy stakeholders, collaborative decision-making processes have been criticized for failing to meet expectations for representative decision making. Indeed, collaborative decision-making processes may effectively perpetuate historical inequalities, despite outward appearances of inclusive participation. For example, in transnational climate change governance, powerful international organizations may coopt collaborative partnerships to promote policy preferences, thereby reinforcing the same hierarchical structures of authority that characterized traditional top-down governance processes (Bäckstrand 2008).

Perceived procedural fairness, defined as the degree to which policy stakeholders regard decision-making processes to be fair, is a key factor in the overall effectiveness of collaborative environmental governance (Schneider et al. 2003, Leach and Sabatier 2005, Berardo 2013, Resh et al. 2014, Siddiki and Goel 2017). When participants have greater faith in the fairness of decision-making processes, they are more likely to trust one another (Siddiki and Goel 2017), reach cooperative agreements
(Lubell 2004, Leach and Sabatier 2005), initiate new collaborative relationships (Resh et al. 2014), and comply with regulations (Winter and May 2001).

However, despite considerable research on how perceived procedural fairness contributes to environmental governance outcomes, there is less understanding of the conditions under which some actors perceive decision-making processes to be fair, whereas others do not (Berardo 2013). This understanding is critical for improving efforts to enhance the legitimacy of decision-making processes, and by extension the effectiveness of environmental governance. A better understanding of the factors that shape perceived procedural fairness can also provide crucial insight into the political behavior of policy stakeholders, including their strategies for choosing decision-making processes that offer the best opportunities for achieving policy goals (Lubell et al. 2017).

I advance this field of research by examining the factors responsible for disparities in actors' perceptions of procedural fairness in task forces, steering committees, and other collaborative environmental policy forums operating within the Lake Victoria basin in East Africa. Although prior research has focused on policy actors' perceptions of the fairness of overall governance systems (Birnbaum et al. 2015), particular policy processes (e.g., estuary partnerships; Berardo 2013), or specific policy forums (Lubell et al. 2017), this study is the first to directly compare perceptions of procedural fairness among actors participating in the same forums. This conceptual focus in turn enables analysis of how differences in forum participants' standing relative to one another (e.g., differences in capacity) relate to differences in their perceptions of the fairness of decisionmaking processes within the forum in which they jointly participate. To test hypotheses about factors that shape perceptions of procedural fairness, the analysis draws upon data 
from a survey of organizational actors involved in environmental policy processes focusing on climate change adaptation within the Lake Victoria basin. The data comprise actors' attributes (e.g., sector, administrative level of operation), as well as two networks: (1) actors' participation in forums (as well as their assessments of those forums) and (2) actors' collaboration with other actors.

The Lake Victoria basin provides an ideal research setting for examining the dynamics of fairness in environmental policy processes. Lake Victoria lies within the borders of Uganda, Kenya, and Tanzania, and policy challenges associated with changing environmental conditions similarly span national boundaries. The region is also the focus of considerable international attention, and a large number of donor organizations and international nongovernmental organizations participate in policy forums, alongside governmental and civil society organizations. Efforts to address environmental challenges at the lake basin level, as well as at national and local levels, result in a multilevel governance system, and policy forums attract participants operating across a similarly broad range of administrative levels. These sources of diversity provide the variance needed to test hypotheses about how disparities in perceived procedural fairness vary according to differences in social capital, resources, and authority among actors jointly participating in the same policy forums.

\section{How environmental governance outcomes hinge upon perceptions of procedural fairness}

Successful environmental governance often requires the mobilization of diverse groups of actors around sets of policies designed to improve environmental quality and societal welfare. These settings are rife with collective action problems, which may relate to the challenges of reconciling opposing preferences held by different stakeholder groups, marshalling informational resources necessary for designing policies in response to rapidly changing environmental conditions, and ensuring that parties follow through on commitments once agreements have been reached.

Research that spans political science and social psychology identifies perceived procedural fairness as a key factor in mitigating these challenges. When decision-making processes are considered to be fair, people are more likely to comply with costly rules, including regulations (Franck 1990, Tyler 2006). Such compliance is particularly important in the implementation of environmental policies, which often redistribute costs among resource users or other stakeholder groups. Prior to implementation phases of the policy process, perceived procedural fairness can temper conflict among policy actors seeking to develop cooperative agreements. When actors have faith in the fairness of deliberative processes, they are more likely to support or accept decisions that do not reflect their policy preferences, but are nevertheless viewed by the group to be constructive and legitimate (Webler and Tuler 2000, Wondolleck and Yaffee 2000, Young 2002, Bolton et al. 2005).

Perceived procedural fairness may be especially important when agreements require buy-in from actors with diverse policy preferences. In these contexts, fairness can promote trust and a group identity among actors that jointly participate in decisionmaking processes, even when actors have historically viewed one another as adversaries (Tyler and Blader 2002, Leach and Sabatier 2005). Such cooperation depends upon familiarity, and when collaborative decision-making processes are perceived to be fair, participants may be more likely to interact with one another. In studies of collaborative dynamics in long-running aquaculture partnerships, Resh and colleagues (2014) found that participants who perceived higher levels of procedural fairness were more likely to have established new professional relationships as a result of the partnership, and Siddiki and Goel (2017) showed that procedural fairness was positively correlated with trust between policy stakeholders. Indeed, research on collaborative environmental policy institutions suggests that their effectiveness in promoting cooperation among participants is linked to participants' confidence in the fairness of decision-making processes (Schneider et al. 2003, Lubell 2004, Leach and Sabatier 2005).

\section{Perceived procedural fairness in transnational environmental governance in developing regions}

There are several reasons why perceived procedural fairness may be particularly important in transnational environmental governance in developing regions. In these settings, decisionmaking processes typically feature the participation of stakeholders that collectively operate over large geographic areas and may be less familiar with one another. Often, participants include representatives of donor or international nongovernmental organizations, which are external to the region that is the focus of policymaking. By virtue of being based in Europe, the United States, or other industrialized regions, these actors are generally less familiar with local political and environmental realities, and frequent staff turnover further limits their ability to develop relationships with local partners (Brinkerhoff 2002). Under these circumstances, in which a lack of familiarity among participants in decision-making processes may limit the likelihood of cooperative agreements, generalized perceptions of procedural fairness may be particularly important for promoting collaboration and trust.

Similarly, environmental policy decision-making processes in developing regions typically involve the participation of stakeholders with varying levels of resources and power. Measures designed to promote procedural fairness can offer a check against the perpetuation of marginalization of groups that have historically been excluded from decision-making processes (Kates 2000, Paavola and Adger 2002, Adger et al. 2006). However, despite outward appearances of inclusivity, decisionmaking processes may nevertheless operate in the "shadow of hierarchy" through mechanisms that magnify the influence of donors, regional governments, and international organizations at the expense of civil society organizations (Bäckstrand 2008). Just because a decision-making process allows for participation of diverse groups of actors does not guarantee that all actors can participate equally (Agarwal 2001, Berkes 2009). Without strong standards of procedural fairness, some stakeholder groups may participate in decision-making processes as observers rather than as genuine partners in policy design. For example, despite inviting nongovernmental organizations to participate in decisionmaking processes, the United Nations Environmental Programme (UNEP) has been criticized for not putting into place stronger rules to ensure that their participation is meaningful, which has raised questions about the legitimacy of the decisionmaking processes it sponsors (Spagnuolo 2009). However, when principles of procedural fairness are truly enshrined in decisionmaking processes, such that less powerful actors can help shape 
policies to the same degree as their more powerful counterparts, not only are the resulting agreements viewed as more legitimate (and as a result, less prone to enforcement problems), but are also potentially better designed. Effective decision-making processes are those that account for a correspondingly diverse set of voices, including those of less powerful groups, which may be able to offer information and perspectives on local realities (Webler 1995, Pahl-Wostl et al. 2007). Such groups may be more willing to participate in decision-making processes they perceive to be fair.

There are additional reasons why perceived procedural fairness is particularly important in climate change adaptation policy processes in transboundary governance systems. The crosscutting nature of climate change impacts compels the integration of adaptation policy with diverse existing policy processes (e.g., pertaining to agriculture, natural resource management, and public health, among many others). The process of mainstreaming adaptation often involves the redistribution of resources (Huq et al. 2004), and decisions may be rejected by actors that perceive them to be unfair. Additionally, transboundary adaptation governance systems span multiple administrative levels, and collaborative policy forums often bring together actors that operate at local, national, regional, and global levels (Adger et al. 2005a, Hamilton et al. 2018). In these settings, actors likewise vary in authority and resources, and higher-level actors may exploit power asymmetries to enhance their influence over decision-making processes at the expense of lower-level actors (Bäckstrand 2008, Gallemore et al. 2015). Such challenges highlight the importance of attending to factors that shape actors' perceptions of procedural fairness.

\section{Social capital, authority, capacity, and the perceived fairness of decision-making processes}

A core theme in research on procedural fairness relates to the interplay between procedural fairness and the social dynamics that operate within decision-making processes. Although an individual may hold a view about the fairness of a particular decision-making process, this perspective is shaped by interactions with other actors that jointly participate in the same process. A literature on policy networks argues that actors leverage social capital to promote agreements that best reflect their policy preferences. Actors with high social capital, e.g., numerous relationships with other actors, are better positioned to draw upon social connections to access information, project policy preferences, and develop coalitions (Granovetter 1985, Adler and Kwon 2002, Fischer and Sciarini 2015).

Although scholarship on policy networks distinguishes between different forms of social capital (Berardo and Scholz 2010, Henry et al. 2011), the network concept of centrality provides a simple and general measure of an actor's ability to leverage relationships. Centrality can refer to an actor's outgoing relationships (i.e., seeking out others, often referred to as "activity"), which can provide opportunities to communicate policy preferences to other actors (Christopoulos 2006, Berardo 2013). Policy actors that are more active may therefore be expected to leverage their relationships to influence decision-making processes in ways that help them achieve policy goals. As a result, more active actors may be more satisfied in the degree to which their policy preferences are represented in decision-making processes and may be more likely to regard these processes as fair. Centrality can also be measured in terms of incoming relationships (i.e., being sought out by others, often referred to as "popularity"). Popularity may signal prestige, and actors with greater social standing may be more likely to be consulted about their preferences during decision-making processes (Berardo 2013, Gebara et al. 2014), thereby increasing their perception of the fairness of such processes. These expectations about the effects of network centrality on perceived procedural fairness motivate two hypotheses:

H1. Among pairs of actors participating in the same forum, more active actors will perceive the forum to have greater procedural fairness compared to less active actors.

$\mathrm{H} 2$. Among pairs of actors participating in the same forum, more popular actors will perceive the forum to have greater procedural fairness compared to less popular actors.

Disparities in perceptions of procedural fairness may likewise correspond to relative differences in authority among actors. In environmental governance, decision-making processes often bring together actors that operate at different spatial or administrative levels. Lebel and colleagues (2005) argued that in such multilevel governance systems, policy actors derive power in part through their ability to shift policymaking from one level to another, and that actors operating at higher administrative levels tend to have greater capacity to do so. Research on comanagement, in which authority is deliberately shared with local stakeholders, suggests that local groups are often still at a disadvantage in decision-making processes in the absence of sustained efforts to improve their standing relative to higher-level actors (Adger et al. 2005b, Armitage 2005, Berkes 2009). Compared to actors operating at higher levels, lower-level actors may have less authority, which limits their influence over decisionmaking processes, resulting in less satisfaction with procedural fairness. These dynamics motivate a third hypothesis:

$\mathrm{H} 3$. Among pairs of actors participating in the same forum, actors operating at lower administrative levels will perceive the forum to have less procedural fairness compared with actors operating at higher levels.

Environmental decision-making processes typically attract the participation of diverse groups of stakeholders, which may include representatives of organizations with varying levels of capacity (Gallemore et al. 2015). The ability to leverage organizational resources can prove instrumental in multistakeholder decision-making processes. In particular, larger organizations can more easily dedicate the staff and financial support (e.g., for travel) necessary to participate regularly in decision-making forums. In turn, regular participation offers opportunities to steadfastly promote a policy agenda in decision-making processes that span multiple meetings, which may increase an actor's satisfaction in the degree to which these processes account for the actors' policy preferences.

H4. Among pairs of actors participating in the same forum, actors with larger staffs will perceive the forum to have greater procedural fairness compared with actors with smaller staffs.

Diversity may also relate to the types of organizations represented by participants in decision-making processes, including governmental organizations, international organizations (donors 
and nongovernmental organizations), and civil society organizations. A core question in research on international development concerns the role of civil society organizations in policy processes because these groups have historically been excluded from, or marginalized when participating in, decisionmaking processes (Amutabi 2013, Sovacool and Linnér 2016). Fisher and Green (2004) argued that civil society organizations tend to be disenfranchised in international environmental governance settings because they must demonstrate their legitimacy and professionalism according to narrow sets of standards established by international institutions. Without formal mechanisms to empower their participation in decisionmaking processes alongside international and governmental organizations, civil society organizations frequently resort to informal tactics to influence decision making (Gemmill and Bamidele-Izu 2002) and may consequently perceive these decisions-making processes to unfairly advantage other actors at their expense.

H5. Among pairs of actors participating in the same forum, civil society actors will perceive less procedural fairness compared with representatives of donor organizations, governmental organizations, and international organizations.

\section{METHODS}

Study system: climate change adaptation governance in the Lake Victoria basin

I analyzed perceived procedural fairness of forums in which stakeholders make decisions about the design and implementation of environmental policies, specifically interventions to address the impacts of climate change on fisheries as well as small-scale agriculture, pastoralism, and biodiversity, in the Lake Victoria basin. Although the basin extends into Rwanda and Burundi, the study focused on portions of the basin within the three riparian nations of Uganda, Kenya, and Tanzania. These three nations not only bear responsibility for managing the land base within the Lake Victoria catchment area, but also the waters of the lake itself. Correspondingly, Uganda, Kenya, and Tanzania face the unique challenge of coordinating the design and implementation of policies to guide the management of a large water body that spans their jurisdictions and is a dominant environmental feature in a region exposed to significant environmental change (Conway 2005, Vervoort et al. 2014). Much of this exposure is related to projected impacts of climate change, which is expected to affect a range of livelihoods, including those dependent on small scale agriculture (Schmidhuber and Tubiello 2007, Jones and Thornton 2009, Thornton et al. 2009a), rangeland systems (Thornton et al. 2009b, Bond and Midgley 2012, Kulmatiski and Beard 2013), and small-scale fisheries (Balirwa 1995, Ficke et al. 2007, Hecky et al. 2010). In response, diverse groups of stakeholders that span administrative levels and sectors have modified or created decision-making forums to coordinate policies to address impacts from changing environmental conditions. The emergence of climate change adaptation as a new environmental policy process operating within the Lake Victoria basin reconfigured the balance of political authority and resources among existing organizations, which underscores the value of fair processes for the allocation of financial and other resources. Likewise, preexisting power asymmetries among policy actors participating in policy forums highlight the importance of procedural fairness (Few et al. 2007).
Data were collected using a survey of representatives of organizations (i.e., policy actors) participating in climate change adaptation policy forums in the Lake Victoria basin. An initial list of organizations, identified through Internet search and review of relevant documents, was reviewed and expanded by members of a steering committee of regional experts from Uganda, Kenya, and Tanzania. Steering committee members similarly reviewed and contributed to a list of respondents identified as focal individuals based on information from organization websites, online meeting notes, and other documents. The survey was administered from February-July 2014. Most respondents were surveyed in person, which offered opportunities for asking follow-up questions to improve qualitative understanding and assist interpretation of analysis. In-person surveys were administered during visits to Kampala, Entebbe, and Jinja in Uganda; Nairobi and Kisumu in Kenya; and Dar es Salaam, Arusha, and Mwanza in Tanzania. In the case of three large organizations, two representatives separately completed the survey. Several respondents wished to participate in the study but were not available during visits to their locations. These individuals completed a web-based version of the survey. In total, representatives of 125 organizations completed the survey in person, and representatives of 19 organizations completed the web-based version, and the American Association for Public Opinion Research (AAPOR) estimated response rate was $59 \%$.

\section{Variables and analytical approaches}

The unit of analysis was a pair (dyad) of organizations jointly participating in a policy forum. For each forum in which they participated, survey respondents were asked "how fair is the process of reaching decisions for all organizations involved?" (response categories ranged from "Very unfair" to "Very fair" on a five-point scale). For each dyad of organizations jointly participating in a particular forum, the dependent variable "Fairness Difference" was calculated as the difference in each organization's perceived level of procedural fairness for that forum (Fig. 1).

Fig. 1. Illustration of differences in perceived procedural fairness between actors participating in a policy forum. Actors are depicted as circles and forums as squares.

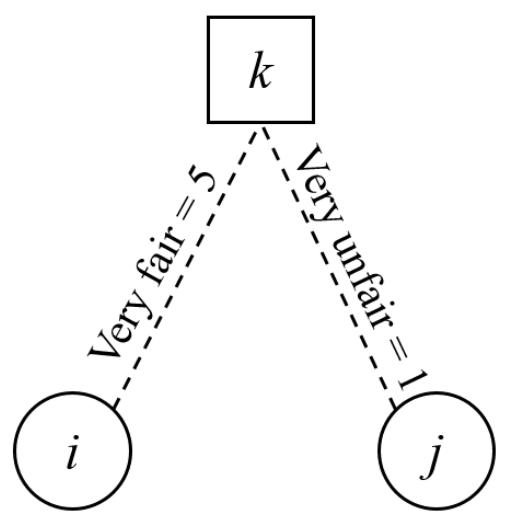

Fairness Difference $_{\mathrm{ijk}}=4$ 
Variables that relate to differences in actors' social capital were measured using data on organizations' collaborative relationships. Respondents were prompted to "list the organizations your organization has collaborated with in the context of climate change adaptation in the past year." These relationships are regarded as outgoing ties. Correspondingly, an organization's incoming ties measure each instance in which another organization identified it as a collaborator. For a dyad of organizations $i j$ participating in forum $k$, a subset of $i$ 's outgoing partners may jointly participate, and a subset of $j$ 's outgoing partners may likewise jointly participate. The variable "WithinForum Activity Difference" was calculated by subtracting the number of organizations in $j$ 's subset from the number of organizations in $i$ 's subset (Fig. 2). The variable "Within-Forum Popularity Difference" was calculated in a similar fashion for incoming (rather than outgoing) relationships. The variable "External Activity Difference" was measured as the difference between the number of actors $i$ and $j$ 's outgoing ties to actors that did not participate in forum $k$. The variable "External Popularity Difference" was measured similarly, but using incoming ties.

Fig. 2. Illustration of differences in activity and popularity between actors participating in a policy forum. Actors are depicted as circles and forums as squares. Participation in forums is indicated by dashed lines and outgoing/incoming collaborative relationships are represented as solid arrows.

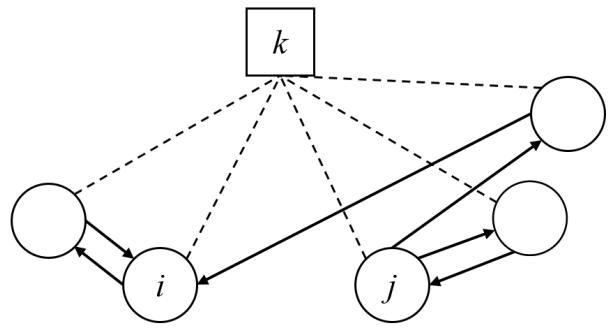

$$
\begin{aligned}
& \text { Activity }_{\mathrm{ik}}=1 ; \text { Activity }_{\mathrm{jk}}=2 ; \text { Activity Difference }_{\mathrm{ijk}}=-1 \\
& \text { Popularity }_{\mathrm{ik}}=2 ; \text { Popularity }_{\mathrm{jk}}=1 ; \text { Popularity Difference }_{\mathrm{ijk}}=1
\end{aligned}
$$

The variable "Level Difference" was calculated by identifying and ranking the administrative levels at which organizations operate (i.e., $1=$ subnational, $2=$ national, $3=$ Lake Victoria basin, $4=$ continental, $5=$ global). The variable was measured by subtracting the level at which organization $j$ operates from the level at which $i$ operates (e.g., if $i$ is a global organization and $j$ a national organization, $5-2=3$ ).

The variable "Staff Size Difference" was measured using data from a survey question that prompted respondents to identify the "approximate number of total staff (full and part-time), currently." Some respondents were unsure of whether certain staff members were full or part-time employees and others were unsure of the approximate staff size of their organizations. Hence, a binary variable was created that indicated whether staff size was above or below the median value of 25 (i.e., $0=$ smaller, $1=$ larger), and missing values were collected using information from organization websites and other publicly available documents. The approach of measuring staff size as a binary variable helped to mitigate the effects of respondents' uncertainty over the specific sizes or their organizations and whether certain individuals were full or part-time employees. Although the possibility remained that some organizations near the threshold might have been classified differently with more accurate information, there was no reason to expect that such potential errors may be correlated with other variables. For each dyad of organizations $i j$, the Staff Size Difference variable was measured as the staff size value of organization $i$ minus the value for organization $j$.

Organizations were also coded according to their sector, and categories included civil society organizations (CSO), development partners (DEVP, i.e., donors), governmental organizations (GOV), international nongovernmental organizations (INGO), and a reference category that included other types of organizations such as research centers and private consulting organizations. Each sector-based variable identified the sector of both organizations in the dyad. For example, the variable "CSODEVP" was measured as 1 if organization $i$ was a civil society organization and $j$ a development partner, and 0 otherwise.

The variable "Age Difference" was included to control for differences in the ages of organizations. A threshold of 20 years was selected to distinguish between organizations established prior to the emergence of climate change adaptation as a global policy issue toward the late 1990s (Orlove 2009). Organizations were coded 1 if older than 20 years and 0 otherwise, and the variable was calculated as the value of organization $i$ minus the value of organization $j$. The variable "Cooperation Difference" was calculated in a similar fashion as "Fairness Difference" and measured the difference between organizations' perception of the level of cooperation in each forum. These data were collected from a survey question that asked: "overall, how would you describe cooperation between organizations" for each forum in which organizations participated. Response categories ranged from "Never cooperate" to "Always cooperate" on a five-point scale.

Because the order of organizations was important for calculating differences (e.g., 5 minus 3 is different from 3 minus 5; CSO-DEVP is different than DEVP-CSO), dyads refer not only to a pair of organizations participating in a forum, but to the order of organizations. Dyads that included duplicate organizations were excluded from the dataset, such that if organizations $i$ and $j$ participated in forum $k$, the dataset only included $i j k$ but not $j i k$. Duplicates were deleted so that each sector-based variable could be included in one form (e.g., for a given pair of organizations including a development partner and a civil society organization, CSO-DEVP was retained whereas DEVP-CSO was dropped). To most directly test Hypothesis 5, which compares civil society organizations to organizations in other sectors, duplicate dyads that included a civil society organization were dropped if the civil society organization followed the other organization. Among dyads that did not include a civil society organization, duplicates were deleted to include development partners first, and among dyads without civil society or development partner organizations, duplicates were deleted to include government organizations first. For dyads of other types of organizations (e.g., both organizations were private consulting groups), in which both organizations were of the same sector, duplicates in which the second organization's name alphabetically preceded the first were deleted. 
A linear regression model was estimated to examine the effects of these variables on differences in perceived procedural fairness. Responses were aggregated for the three cases in which two representatives were surveyed on behalf of their large organizations. Because organizations could appear multiple times as either the first or second member of a dyad (i.e., as $i$ or $j$ ), and because the same forum could appear multiple times as well, errors were clustered around organizations in both the $i$ and $j$ positions as well as around forums.

\section{RESULTS}

Results do not support H1 (more active organizations would perceive greater procedural fairness) but do support H2 (more popular organizations would perceive greater procedural fairness; Table 1). The coefficient for Within-Forum Popularity Difference indicates that for a pair of organizations that both participate in a policy forum, the organization identified as a collaborator by a greater number of other forum participants perceives a higher level of procedural fairness in that forum.

Table 1. Regression model of the difference in perceived procedural fairness between organizations jointly participating in environmental policy forums. Note: $\mathrm{CSO}=$ civil society organizations; DEVP = development partners; GOV = governmental organizations; INGO = international nongovernmental organization.

\begin{tabular}{lc}
\hline \hline & Estimate (SE) \\
\hline (Intercept) & $0.02(0.07)$ \\
Within-Forum Activity Difference & $-0.02(0.03)$ \\
Within-Forum Popularity Difference & $0.03(0.01)^{* *}$ \\
Level Difference & $0.18(0.08)^{*}$ \\
Staff Size Difference & $0.31(0.11)^{* *}$ \\
CSO-DEVP & $-0.88(0.23)^{* * *}$ \\
CSO-GOV & $-0.00(0.16)$ \\
CSO-INGO & $0.15(0.17)$ \\
DEVP-GOV & $0.58(0.29)^{*}$ \\
DEVP-INGO & $0.97(0.26)^{* * *}$ \\
GOV-INGO & $0.43(0.27)$ \\
External Activity Difference & $-0.05(0.02)^{* *}$ \\
External Popularity Difference & $-0.01(0.00)^{* * *}$ \\
Age Difference & $-0.21(0.07)^{* *}$ \\
Cooperation Difference & $0.26(0.06)^{* * *}$ \\
Adjusted R ${ }^{2 *}$ & 0.21 \\
\hline Significance levels: ${ }^{* * *} p<0.001,{ }^{* *} p<0.01,{ }^{*} p<0.05$.
\end{tabular}

Coefficients for Level Difference and Staff Size Difference indicate that organizations operating at higher administrative levels and that have larger staffs indeed perceive greater procedural fairness, providing support for $\mathrm{H} 3$ and $\mathrm{H} 4$. Results provide mixed support for H5 (civil society organizations would perceive less procedural fairness compared to development partners, governmental organizations, and international NGOs). The coefficient for CSO-DEVP indicates that when a civil society organization and development partner jointly participate in a forum, the civil society organization perceives less procedural fairness than the development partner. Indeed, the DEVP-GOV and DEVP-INGO coefficients show that development partners likewise perceive greater procedural fairness than government actors and international NGOs. However, results for CSO-GOV and CSO-INGO indicate that civil society organizations did not perceive less procedural fairness compared to government actors and international NGOs, as had been expected.

While completing the survey, many respondents shared experiences and perspectives that help to contextualize findings from statistical analysis. These responses were primarily prompted by the question "how fair is the process of reaching decisions for all organizations involved?", which also elicited the data used to measure the dependent variable in the analysis. For the 87 respondents who consented to be recorded, responses to this question were transcribed and de-identified. Two additional subjects did not complete the survey but were interviewed on the basis of their extensive involvement in environmental governance activities within the Lake Victoria basin. Portions of these two interviews in which the subjects reflected on issues of procedural fairness were likewise transcribed and de-identified.

Many respondents spoke about the roles of development partners relative to other types of policy actors. For example, one respondent's comments suggest that development partners may perceive decision-making processes to be fairer because they have different expectations about what degree of participation is sufficient to legitimize decisions.

\section{It's very fair, because you have to have the stakeholder consultations... everybody gets to air what they have to say but there are some donors that have a larger voice in a way. (Development partner 41)}

Although some development partners may view consultations as indication of procedural fairness, forum participants with "smaller voices" may feel unable to make meaningful contributions to decision-making processes. Representatives of civil society organizations echoed this idea that participation and fairness are not synonymous. One such respondent described the challenge of contributing to decision making at a recent United Nations Climate Change Conference:

\section{If you participate as a CSO, you have an observer badge, so you don't participate in all meetings, you are not following. You cannot engage in all meetings. Some of them are closed. (Civil society organization 43)}

This individual contrasted this experience with a different policy forum, in which decision-making processes were considered to be fairer.

They have a slot of CSO dialog. And they give us opportunities to present our views from our countries, but they also give us opportunities to provide recommendations. And we've been providing recommendations on how to improve. (Civil society organization 43 )

Without these mechanisms, actors that lack formal authority (e.g., nongovernmental organizations) or financial resources (e.g., local organizations) may need to draw upon more entrepreneurial strategies for contributing to decision-making processes.
After we have initiated collaboration with them, that's when they tried to include us. Before that it was unfair. But after our initiative, they now consider us. (Civil society organization 43)

Respondents also described how perceptions of procedural fairness relate to organizational resources, such as expertise. 
It's fair.. maybe it's because I'm the expert, and I know what I'm saying. And that makes a big difference. If you don't have a person with authority in certain subjects, then everybody is equal. 'You're right, you're wrong, you're right, you're wrong.' (International NGO 133)

In this case, the respondent assessed the decision-making process to be fair because other participants deferred to technical expertise. Another representative of an international NGO described how local organizations seek to overcome such challenges by adopting the language used by actors in the international community.

Unfortunately, often the real local knowledge doesn't really get very far in this system because the enormous juggernaut of these things tends to shape everything. The way [local organizations] frame things has to be in a certain way... What's really powerful is the way stories are being told. Who gets to write the script? Who is then using that script? (International NGO 140)

\section{DISCUSSION}

This study's findings indicate that actors with greater social capital, capacity, and authority perceive decision-making processes to be fairer than do their less advantaged counterparts that participate in the same environmental policy forums.

One measure of an actor's social capital is the number of joint forum participants that identify the actor as a collaborator (i.e., the actor's within-forum popularity). Relative to other forum participants, actors with greater within-forum popularity perceived greater procedural fairness. However, the gap between actors' within-forum activity (i.e., the number of outgoing collaborative relationships to joint forum participants) had no significant effect on different levels of perceived procedural fairness. Meanwhile, assessments of procedural fairness were actually lower for actors with higher social capital external to the forum, as measured by the number of outgoing and incoming relationships with actors that did not participate in the forum (external activity and external popularity, respectively). Taken together, these findings highlight the importance of analyzing decision-making processes as part of the broader governance system. For example, although prior research did not find a significant relationship between perceived procedural fairness and an actor's popularity (Berardo 2013), the present study distinguishes between popularity within and external to each forum under evaluation, showing that the two measures of social capital have opposing effects on perceived procedural fairness. For actors that strategically allocate time and resources among multiple environmental policy forums (Mewhirter et al. 2018), these findings suggest that the benefits of cultivating social influence within a particular policy forum may not extend to other forums, and that actors that prioritize certain forums may perceive less fairness in decision-making processes in other forums. This trade-off is consistent with the observation by Leach and Sabatier (2005) that when social capital is spread too thin, environmental policy actors lack the time and resources to commit to decisionmaking processes in ways that facilitate the development of trust and cooperation, which was a strong predictor of procedural fairness in the present study.

Disparities in actors' perceptions of procedural fairness also varied as a function of differences in their capacity (measured by staff size) and administrative level of operation. These findings highlight a core challenge facing efforts to broaden participation in collaborative environmental decision-making processes: although such processes may be open to diverse participation, they may still reflect traditional power structures that afford a subset of actors disproportionate influence over decisions (Bäckstrand 2008). Consequently, to contribute to environmental decision-making processes, less powerful actors must first demonstrate their legitimacy according to standards set by international actors (Fisher and Green 2004). In climate change adaptation policy processes, one source of legitimacy is access to scientific expertise, which may be concentrated among larger organizations and/or organizations operating at higher administrative levels (e.g., International NGO 133, whose representative noted: "It's fair... maybe because I'm the expert..."). By contrast, representatives of smaller and more local organizations are typically better able to contribute place-based knowledge to decision-making processes (Pomeroy and Berkes 1997, Davidson-Hunt and O'Flaherty 2007). In policy forums that emphasize technical expertise at the expense of local knowledge, such organizations may regard decision-making processes as less fair. Consequently, these forums may miss key opportunities to design environmental policies that account for local realities.

This study also examined how perceptions of procedural fairness vary between civil society organizations and other types of actors and found that CSOs considered decision-making processes to be less fair than did development partners (i.e., donor organizations), but not government organizations or international nongovernmental organizations (NGOs). Indeed, government organizations and international NGOs also perceived significantly less procedural fairness compared with development partners. Consistent with research linking status with perception of procedural fairness (Tyler and Blader 2002, Chen et al. 2003), development partners may perceive greater procedural fairness because of their central role in guiding policy by setting conditions under which foreign aid can support development goals (Reith 2010).

More broadly, these findings have implications for the performance of decentralized environmental governance systems, which typically feature numerous and interdependent decisionmaking forums. In these settings, actors strategically participate in the subset of forums that offer the best opportunities to achieve their policy goals (Lubell 2013). Correspondingly, actors may abandon forums in which they are unable to influence decisions. To the extent that actors enter and exit policy forums on the basis of perceived procedural fairness, this study's findings suggest that such actions may result in decision-making processes in which participants operate at the same administrative levels, represent organizations of similar sizes, and are otherwise homogenous. Over time, this dynamic may erode connectivity among the set of policy forums within the overall governance system, which may in turn reduce capacity to marshal a cohesive regional response to complex and/or emerging challenges, such as climate change (Vervoort et al. 2014).

Substantively, these findings have implications for environmental decision-making processes within the Lake Victoria region. In particular, results highlight the need for institutional mechanisms that raise the profile of smaller and more local organizations, and especially civil society organizations. For decision-making 
processes to be regarded as fair, they must include opportunities for all participants to influence decisions about the design and implementation of policy, beyond merely having a seat at the table or being consulted during the initial phases of decision making. For example, the fact that civil society organizations do not perceive significantly less fairness relative to state actors and representatives of international nongovernmental organizations is a sign of progress in efforts to level the playing field and provide opportunities for meaningful participation of civil society organizations, which have traditionally been marginalized in policy processes in East Africa (Amutabi 2013, Sovacool and Linnér 2016). However, civil society organizations nevertheless assess procedural fairness significantly less favorably than development partners, suggesting that governance led by foreign aid agencies may not be "up-scaling" local or national policy processes in ways that enfranchise civil society actors (Börzel and Risse 2016). Meaningful participation may hinge upon the institutionalization of mechanisms explicitly designed to incorporate information, perspectives, and preferences of diverse policy actors, including smaller and more local organizations. Such mechanisms may include repeated consultations with diverse stakeholders over the course of policy design and implementation as well as the institutionalization of formalized opportunities for such groups to submit recommendations for consideration in decision-making processes. Likewise, the relationship between perceived procedural fairness and popularity highlights the prospective value of efforts to help smaller and more local organizations build social capital (e.g., by subsidizing their regular participation) in forums that may otherwise be dominated by larger and more international organizations.

\section{CONCLUSION}

This study examined why actors jointly participating in environmental policy forums operating within the Lake Victoria basin have different perceptions of the fairness of those forums. Results indicate that among pairs of actors involved in any given forum, satisfaction with procedural fairness tends to be greater for those actors with more social capital (particularly, incoming ties from other actors), operating at a higher administrative level, and with larger staff size. Additionally, civil society organizations perceived less procedural fairness compared to development partners (i.e., donor organizations). Although a sizeable literature demonstrates the importance of perceived procedural fairness in explaining the performance of policy networks, there has been limited research on the factors that shape perceived fairness itself among actors in policy networks. In showing that an actors' standing relative to one another accounts for differences in their assessments of perceived procedural fairness, this study highlights the need for greater clarity on how dynamics operating within and between decision-making processes shape perceived procedural fairness. Of particular value will be future research that examines how perceptions of fairness shape actors' decisions to shift participation among the large set of forums that comprise environmental governance systems.

Responses to this article can be read online at: http://www.ecologyandsociety.org/issues/responses. php/10625

\section{Acknowledgments:}

I thank Emilinah Namaganda, Shuaib Lwasa, Paul Onyango, and Charles Mundia for valuable recommendations and logistical assistance preceding and during fieldwork. An earlier version of this paper was presented at the 2017 Water, Inclusion and Visions of Development workshop in Stockholm, Sweden, and the paper benefited from discussants' feedback. I additionally thank Maria Mancilla Garcia and Karin Ingold for helpful comments on earlier drafts of the paper. Research was partially supported by NSF Division of Graduate Education (DGE) \#0801430, the Responding to Rapid Environmental Change (REACH) IGERT awarded to UC Davis, and a Jastro-Shields grant from UC Davis.

\section{LITERATURE CITED}

Adger, W. N., J. Paavola, S. Huq, and M. J. Mace. 2006. Fairness in adaptation to climate change. MIT Press, Cambridge, Massachusetts, USA.

Adger, W. N., N. W. Arnell, and E. L. Tompkins. 2005a. Successful adaptation to climate change across scales. Global Environmental Change 15(2):77-86. http://dx.doi.org/10.1016/i.gloenvcha.2004.12.005

Adger, W. N., K. Brown, and E. L. Tompkins. 2005b. The political economy of cross-scale networks in resource co-management. Ecology and Society 10(2):9. http://dx.doi.org/10.5751/ES-01465-100209

Adler, P. S., and S.-W. Kwon. 2002. Social capital: prospects for a new concept. Academy of Management Review 27(1):17-40. http://dx.doi.org/10.5465/amr.2002.5922314

Agarwal, B. 2001. Participatory exclusions, community forestry, and gender: an analysis for South Asia and a conceptual framework. World Development 29(10):1623-1648. http://dx.doi. org/10.1016/S0305-750X(01)00066-3

Amutabi, M. N. 2013. The NGO factor in Africa: the case of arrested development in Kenya. Routledge, New York, New York, USA.

Ansell, C., and A. Gash. 2008. Collaborative governance in theory and practice. Journal of Public Administration Research and Theory 18(4):543-571. http://dx.doi.org/10.1093/jopart/mum032

Armitage, D. 2005. Adaptive capacity and community-based natural resource management. Environmental Management 35 (6):703-715. http://dx.doi.org/10.1007/s00267-004-0076-Z

Armitage, D., M. Marschke, and R. Plummer. 2008. Adaptive comanagement and the paradox of learning. Global Environmental Change 18(1):86-98. http://dx.doi.org/10.1016/j.gloenvcha.2007.07.002

Bäckstrand, K. 2008. Accountability of networked climate governance: the rise of transnational climate partnerships. Global Environmental Politics 8(3):74-102. http://dx.doi.org/10.1162/ glep.2008.8.3.74

Balirwa, J. S. 1995. The Lake Victoria environment: its fisheries and wetlands - a review. Wetlands Ecology and Management 3 (4):209-224. http://dx.doi.org/10.1007/BF00179837

Berardo, R. 2013. The coevolution of perceptions of procedural fairness and link formation in self-organizing policy networks. Journal of Politics 75(3):686-700. http://dx.doi.org/10.1017/ $\underline{\mathrm{S} 0022381613000455}$ 
Berardo, R., and J. T. Scholz. 2010. Self-organizing policy networks: risk, partner selection, and cooperation in estuaries. American Journal of Political Science 54(3):632-649. https://doi. org/10.1111/j.1540-5907.2010.00451.x

Berkes, F. 2009. Evolution of co-management: role of knowledge generation, bridging organizations and social learning. Journal of Environmental Management 90(5):1692-1702. http://dx.doi. org/10.1016/j.jenvman.2008.12.001

Birnbaum, S., Ö. Bodin, and A. Sandström. 2015. Tracing the sources of legitimacy: the impact of deliberation in participatory natural resource management. Policy Sciences 48(4):443-461. http://dx.doi.org/10.1007/s11077-015-9230-0

Bolton, G. E., J. Brandts, and A. Ockenfels. 2005. Fair procedures: evidence from games involving lotteries. Economic Journal 115 (506):1054-1076. http://dx.doi.org//10.1111/j.1468-0297.2005.01032. $\underline{\mathrm{x}}$

Bond, W. J., and G. F. Midgley. 2012. Carbon dioxide and the uneasy interactions of trees and savannah grasses. Philosophical Transactions of the Royal Society B: Biological Sciences 367 (1588):601-612. http://dx.doi.org/10.1098/rstb.2011.0182

Börzel, T. A., and T. Risse. 2016. Dysfunctional state institutions, trust, and governance in areas of limited statehood. Regulation and Governance 10(2):149-160. http://dx.doi.org/10.1111/rego.12100

Brinkerhoff, J. M. 2002. Partnership for international development: rhetoric or results? Lynne Rienner, Boulder Colorado, USA.

Chen, Y.-R., J. Brockner, and J. Greenberg. 2003. When is it "a pleasure to do business with you?" The effects of relative status, outcome favorability, and procedural fairness. Organizational Behavior and Human Decision Processes 92(1):1-21. http://dx.doi. org/10.1016/S0749-5978(03)00062-1

Christopoulos, D. C. 2006. Relational attributes of political entrepreneurs: a network perspective. Journal of European Public Policy 13(5):757-778. http://dx.doi.org/10.1080/13501760600808964

Conway, D. 2005. From headwater tributaries to international river: observing and adapting to climate variability and change in the Nile basin. Global Environmental Change 15(2):99-114. http://dx.doi.org/10.1016/j.gloenvcha.2005.01.003

Davidson-Hunt, I. J., and R. M. O'Flaherty. 2007. Researchers, indigenous peoples, and place-based learning communities. Society and Natural Resources 20(4):291-305. http://dx.doi. org/10.1080/08941920601161312

Few, R., K. Brown, and E. L. Tompkins. 2007. Public participation and climate change adaptation: avoiding the illusion of inclusion. Climate Policy 7(1):46-59. http://dx.doi. org/10.1080/14693062.2007.9685637

Ficke, A. D., C. A. Myrick, and L. J. Hansen. 2007. Potential impacts of global climate change on freshwater fisheries. Reviews in Fish Biology and Fisheries 17(4):581-613. http://dx.doi. org/10.1007/s11160-007-9059-5

Fischer, M., and P. Sciarini. 2015. Unpacking reputational power: intended and unintended determinants of the assessment of actors' power. Social Networks 42:60-71. http://dx.doi. org/10.1016/j.socnet.2015.02.008
Fisher, D. R., and J. F. Green. 2004. Understanding disenfranchisement: civil society and developing countries' influence and participation in global governance for sustainable development. Global Environmental Politics 4(3):65-84. http://dx. doi.org/10.1162/1526380041748047

Franck, T. M. 1990. The power of legitimacy among nations. Oxford University Press, Oxford, UK.

Gallemore, C., M. Di Gregorio, M. Moeliono, M. Brockhaus, and R. D. Prasti. 2015. Transaction costs, power, and multi-level forest governance in Indonesia. Ecological Economics 114:168-179. http://dx.doi.org/10.1016/j.ecolecon.2015.03.024

Gebara, M. F., L. Fatorelli, P. May, and S. Zhang. 2014. REDD+ policy networks in Brazil: constraints and opportunities for successful policy making. Ecology and Society 19(3):53. http://dx. doi.org/10.5751/ES-06744-190353

Gemmill, B., and A. Bamidele-Izu. 2002. The role of NGOs and civil society in global environmental governance. Pages 1-24 in D. C. Etsy and M. H. Ivanova, editors. Global environmental governance: options and opportunities. Yale Center for Environmental Law and Policy, New Haven, Connecticut, USA. [online] URL: https://environment.yale.edu/publication-series/ documents/downloads/a-g/gemmill.pdf

Granovetter, M. 1985. Economic action and social structure: the problem of embeddedness. American Journal of Sociology 91 (3):481-510. https://doi.org/10.1086/228311

Hamilton, M., M. Lubell, and E. Namaganda. 2018. Cross-level linkages in an ecology of climate change adaptation policy games. Ecology and Society 23(2):36. http://dx.doi.org/10.5751/ ES-10179-230236

Hecky, R. E., R. Mugidde, P. S. Ramlal, M. R. Talbot, and G. W. Kling. 2010. Multiple stressors cause rapid ecosystem change in Lake Victoria. Freshwater Biology 55:19-42. http://dx.doi. org/10.1111/j.1365-2427.2009.02374.x

Henry, A. D., M. Lubell, and M. McCoy. 2011. Belief systems and social capital as drivers of policy network structure: the case of California regional planning. Journal of Public Administration Research and Theory 21(3):419-444. https://doi.org/10.1093/ jopart/muq042

Huq, S., H. Reid, M. Konate, A. Rahman, Y. Sokona, and F. Crick. 2004. Mainstreaming adaptation to climate change in least developed countries (LDCs). Climate Policy 4(1):25-43. http://dx. doi.org/10.1080/14693062.2004.9685508

Jones, P. G., and P. K. Thornton. 2009. Croppers to livestock keepers: livelihood transitions to 2050 in Africa due to climate change. Environmental Science and Policy 12(4):427-437. http:// dx.doi.org/10.1016/j.envsci.2008.08.006

Kates, R. W. 2000. Cautionary tales: adaptation and the global poor. Climatic Change 45(1):5-17. http://dx.doi.org/10.1007/978-94-017-3010-5 2

Kulmatiski, A., and K. H. Beard. 2013. Woody plant encroachment facilitated by increased precipitation intensity. Nature Climate Change 3(9):833-837. http://dx.doi.org/10.1038/ nclimate1904 
Leach, W. D., and P. A. Sabatier. 2005. To trust an adversary: integrating rational and psychological models of collaborative policymaking. American Political Science Review 99(04):491-503. http://dx.doi.org/10.1017/S000305540505183X

Lebel, L., P. Garden, and M. Imamura. 2005. The politics of scale, position, and place in the governance of water resources in the Mekong region. Ecology and Society 10(2):18. [online] URL: http://www.ecologyandsociety.org/vol10/iss2/art18/

Lubell, M. 2004. Collaborative environmental institutions: all talk and no action? Journal of Policy Analysis and Management 23(3):549-573. http://dx.doi.org/10.1002/pam.20026

Lubell, M. 2013. Governing institutional complexity: the ecology of games framework. Policy Studies Journal 41(3):537-559. http:// dx.doi.org/10.1111/psj.12028

Lubell, M., J. M. Mewhirter, R. Berardo, and J. T. Scholz. 2017. Transaction costs and the perceived effectiveness of complex institutional systems. Public Administration Review 77 (5):668-680. http://dx.doi.org/10.1111/puar.12622

Mewhirter, J., M. Lubell, and R. Berardo. 2018. Institutional externalities and actor performance in polycentric governance systems. Environmental Policy and Governance 28(4):295-307. http://dx.doi.org/10.1002/eet.1816

Orlove, B. 2009. The past, the present and some possible futures of adaptation. Pages 131-163 in W. N. Adger, I. Lorenzoni, and K. O'Brien, editors. Adapting to climate change: thresholds, values, governance. Cambridge University Press, Cambridge, UK. http:// dx.doi.org/10.1017/CBO9780511596667.010

Paavola, J., and W. N. Adger. 2002. Justice and adaptation to climate change. Tyndall Centre working paper 23. Tyndall Centre for Climate Change Research, Manchester, UK.

Pahl-Wostl, C., M. Craps, A. Dewulf, E. Mostert, D. Tabara, and T. Taillieu. 2007. Social learning and water resources management. Ecology and Society 12(2):5. http://dx.doi. org/10.5751/ES-02037-120205

Pomeroy, R. S., and F. Berkes. 1997. Two to tango: the role of government in fisheries co-management. Marine Policy 21 (5):465-480. http://dx.doi.org/10.1016/S0308-597X(97)00017-1

Reith, S. 2010. Money, power, and donor-NGO partnerships. Development in Practice 20(3):446-455. http://dx.doi. org/10.1080/09614521003709932

Resh, W., S. Siddiki, and W. R. McConnell. 2014. Does the network centrality of government actors matter? Examining the role of government organizations in aquaculture partnerships. Review of Policy Research 31(6):584-609. http://dx.doi. org/10.1111/ropr.12101

Schmidhuber, J., and F. N. Tubiello. 2007. Global food security under climate change. Proceedings of the National Academy of Sciences 104(50):19703-19708. http://dx.doi.org/10.1073/pnas.0701976104

Schneider, M., J. Scholz, M. Lubell, D. Mindruta, and M. Edwardsen. 2003. Building consensual institutions: networks and the National Estuary Program. American Journal of Political Science 47(1):143-158. http://dx.doi.org/10.1111/1540-5907.00010
Siddiki, S., and S. Goel. 2017. Assessing collaborative policymaking outcomes: an analysis of U.S. Marine Aquaculture Partnerships. American Review of Public Administration 47 (2):253-271. http://dx.doi.org/10.1177/0275074015599603

Sovacool, B., and B.-O. Linnér. 2016. The political economy of climate change adaptation. Palgrave Macmillan, New York, New York, USA. http://dx.doi.org/10.1057/9781137496737

Spagnuolo, F. 2009. Beyond participation: administrative-law type mechanisms in global environmental governance: toward a new basis of legitimacy scrutiny. European Public Law 15:49-62.

Thornton, P. K., P. G. Jones, G. Alagarswamy, and J. Andresen. 2009a. Spatial variation of crop yield response to climate change in East Africa. Global Environmental Change 19(1):54-65. http:// dx.doi.org/10.1016/j.gloenvcha.2008.08.005

Thornton, P. K., J. van de Steeg, A. Notenbaert, and M. Herrero. 2009b. The impacts of climate change on livestock and livestock systems in developing countries: a review of what we know and what we need to know. Agricultural Systems 101(3):113-127. http://dx.doi.org/10.1016/j.agsy.2009.05.002

Tyler, T. R. 2006. Why people obey the law. Princeton University Press, Princeton, New Jersey, USA.

Tyler, T. R., and S. L. Blader. 2002. Autonomous vs. comparative status: must we be better than others to feel good about ourselves? Organizational Behavior and Human Decision Processes 89 (1):813-838. http://dx.doi.org/10.1016/S0749-5978(02)00031-6

Vervoort, J. M., P. K. Thornton, P. Kristjanson, W. Förch, P. J. Ericksen, K. Kok, J. S. I. Ingram, M. Herrero, A. Palazzo, A. E. S. Helfgott, A. Wilkinson, P. Havlík, D. Mason-D'Croz, and C. Jost. 2014. Challenges to scenario-guided adaptive action on food security under climate change. Global Environmental Change 28:383-394. http://dx.doi.org/10.1016/j.gloenvcha.2014.03.001

Webler, T. 1995. "Right" discourse in civic participation: an evaluative yardstick. Pages 35-86 in O. Renn, T. Webler, and P. M. Wiedemann, editors. Fairness and competence in citizen participation: evaluating models for environmental discourse. Springer, Dordrecht, The Netherlands. https://doi. org/10.1007/978-94-011-0131-8 3

Webler, T., and S. Tuler. 2000. Fairness and competence in citizen participation: theoretical reflections from a case study. Administration and Society 32(5):566-595. http://dx.doi. org/10.1177/00953990022019588

Winter, S. C., and P. J. May. 2001. Motivation for compliance with environmental regulations. Journal of Policy Analysis and Management 20(4):675-698. http://dx.doi.org/10.1002/pam.1023

Wondolleck, J. M., and S. L. Yaffee. 2000. Making collaboration work: lessons from innovation in natural resource management. Island, Washington, D.C., USA.

Young, I. M. 2002. Inclusion and democracy. Oxford University Press, Oxford, UK. 